IOS Press

\title{
Erratum
}

\section{Unexpected aggressive behaviour: Interaction of bupropion and alcohol}

Percy Chandler and Andrew Herxheimer

[International Journal of Risk \& Safety in Medicine 23(3) (2011), 133-137]

In the Abstract of this article, line 2, the words " 8 at end" should not be there. The sentence should read:

"Though it had given him headaches and insomnia he tried using it again in 2009, taking $150 \mathrm{mg} /$ day." 